\title{
KEMAMPUAN IBU POSTPARTUM PRIMIPARA REMAJA DALAM MENYUSUI BAYI BARU LAHIR DI WILAYAH KERJA UPT BLUD PUSKESMAS NARMADA KABUPATEN LOMBOK BARAT NTB 2017
}

\author{
Baiq Yuni Fitri Hamidiyanti \\ Jurusan Kebidanan, Poltekkes Kemenkes Mataram
}

\begin{abstract}
ABSTRAK
Transisi menjadi orang tua akan sulit bagi orang tua yang masih remaja, ibu primipara remaja pada minggu pertama masih belum siap menerima tugas-tugas barunya sebagai ibu. Ibu Primipara remaja sering tmengalami perasaan tidak mahir dan tidak mampu dalam melakukan keterampilan perawatan bayi, misalnya memberikan ASI atau menyusui bayi. Penelitian ini bertujuan untuk mengetahui kemampuan ibu postpartum primipara remaja dalam menyusui bayi baru lahir. Jenis penelitian observasional dengan rancangan cross sectional. Populasi penelitian seluruh ibu postpartum primipara remaja bersalin di Wilayah Kerja Puskesmas Narmada bulan Mei sampai Juli 2017, teknik pengambilan sampel menggunakan purposive sampling jumlah sampel diperoleh sebanyak 40 responden. Uji statistik yang digunakan adalah Uji regresi linear. Hasil penelitian menunjukkan ada pengaruh kemampuan menyusui bayi baru lahir pada hari ke 3 dengan berat badan bayi pada hari ke 3, dengan $p=0,000$ atau $p<0,05$, dengan nilai koefisien regresi sebesar $R=0,576$. Hasil pada hari ke 7 ada pengaruh kemampuan menyusui bayi baru lahir pada hari ke 7 dengan berat badan bayi pada hari ke 7 , dengan $\mathrm{p}=0,000$ atau $\mathrm{p}<0,05$. Kesimpulan penelitian ada pengaruh yang signifikan kemampuan menyusui bayi baru lahir dengan perkembangan berat bada bayi baru lahir.
\end{abstract}

Kata Kunci: kemampuan, primipara remaja, menyusui bayi baru lahir

\begin{abstract}
Transitioning to parent will be difficult for teenage parents, teenage primiparous moms in the first week are still not ready to accept her new duties as a mother. Primipara's mothers often have feelings of inadequacy and inability to perform baby care skills, such as breastfeeding or breastfeeding. This study aims to determine the ability of postpartum primipara adolescent mothers in breastfeeding newborns. Type of observational study with cross sectional design. The study population of all postpartum primipara maternal adolescents in Narmada Puskesmas Working Area from May to July 2017, sampling technique using purposive sampling the number of samples obtained as many as 40 respondents. The statistical test used is linear regression test. The results showed that there was influence of the ability to breastfeed newborn on the $3 r d$ day with infant weight on day 3 , with $p=0.000$ or $p<0,05$, with regression coefficient value equal to $R=0,576$. Results on the 7 th day was the effect of the ability to breastfeed newborns on the 7th day with infant weight on day 7, with $p=0.000$ or $p<0.05$. The conclusion of the study there is a significant influence of the ability to breastfeed newborns with the development of newborn bada weight.
\end{abstract}

Keywords: ability, primipara adolescent, breastfeeding newborn baby 


\section{PENDAHULUAN}

Indikator kesejahteraan suatu bangsa salah satunya diukur dari besarnya angka kematian (mortalitas). Makin tinggi angka tersebut, maka makin rendah kesejahteraan suatu bangsa. Disamping menunjukkan derajat kesehatan dan tingkat kesejahteraan masyarakat, angka tersebut juga menunjukkan kualitas pelayanan kesehatan masyarakat. Berdasarkan Survei Demografi Kesehatan Indonesia (SDKI) tahun 2012 Angka Kematian Bayi (AKB) masih tinggi mencapai 32 per 1000 Kelahiran Hidup (KH), dimana tujuan Pembangunan Millenuim Development Goals (MDGs) tahun 2000 - 2015 menurunkan AKB menjadi 23 per 100.000 $\mathrm{KH}$ belum tercapai karena memerlukan akses seluruh bayi terhadap intervensi kunci seperti ASI eksklusif. Kemudian dilanjutkan dengan Sustainable Development Goals (SDGs) 2015 2030 menurunkan AKB 12 per $1.000 \mathrm{KH}$ (Kemnkes, 2015).

Jumlah kematian Bayi di Provinsi NTB tahun 2016 mecapai 1.006 kasus, di Kabupaten Lombok Barat sebesar 38 kasus (Dikes Provinsi NTB, 2016). Dari Profil Kesehatan Kabupaten Lombok Barat (2015) Penyebab kematian bayi disebabkan oleh BBLR 29\%, Asfiksia 14\%, Kelainan Kongenital 11\%,

ISPA/Pnuemonia 7\%, sepsis $5 \%$, kelainan cerna $4 \%$, kelainan syaraf $2 \%$, dan Lainnya $31 \%$. Seiring dengan meningkatnya angka kematian bayi, maka semakin bertambah pula tanggungjawab masyarakat khususnya ibu sebagai orang tua untuk ikut berperan dalam menurunkan angka kematian dan kesakitan pada bayi (Kemenkes, 2013). Menurut Ridha (2014) dalam Hamidiyanti (2015) hal ini ditunjukkan bagaimana seorang ibu berperan dalam merawat bayinya dirumah melakukan perawatan tali pusat, menyusui bayi, memandikan bayi, mengganti dan mengenakan popok menggendong bayi, memeriksakan kesehatan anak, imunisasi dan lain sebagainya. Perawatan yang kurang baik akan berdampak pada pertumbuhan dan perkembangan anak.

Dikutip dari suara NTB (Kamis, 27 Juli 2017) kepala Bidang Pengendalian Penduduk, Penyuluhan dan Penggerakan (P4) pada Dinas Pengendalian Penduduk dan KB, Pemberdayaan Perempuan dan Perlindungan Anak (P2KNP3A) Lombok Barat, angka pernikahan dini di bawah usia 16-21 tahun di Lobar masih tinggi mencapai $50 \%$ lebih, bahkan pernikahan di usia 16 tahun ke bawah. SDKI 2012 angka kelahiran usia remaja 15-19 tahun sebesar 48 per 1.000 kelahiran, sedangkan di Propinsi NTB angka kelahiran cukup tinggi yaitu sebesar 75 per 1.000 kelahiran. Melalui pengembangan program ketahanan keluarga remaja target pada SDKI 2019 ASFR dapat turun menjadi 30/1.000 KH. (Riskesdas, 2013). Berdasarkan studi pendahuluan yang dilakukan di Wilayah Kerja Puskesmas Narmada jumlah ibu bersalin primipra remaja usia 10-19 tahun pada 2015 adalah 127persalinan dari 926 persalinan dan tahun 2016 terdapat 
135 persalinan dari 916 persalinan.. Berdasarkan data diatas memberikan gambaran bahwa tingginya angka umur perempuan yang menikah pada usia remaja dan masih tingginya angka kelahiran anak dari perempuan usia remaja.

Primipara adalah wanita yang baru pertmakali mempunyai anak hidup dan baru menjadi seorang ibu. Beberapa ibu primipara biasanya mempunyai keinginan untuk melahirkan bayi yang bebas dari gangguan, sehingga hal tersebut akan memotivasi ibu untuk mencari pengetahuan banyak tentang perawatan maternal. Ibu primipara memiliki keinginan yang kuat untuk dapat memberikan ASI pada bayinya. Hasil penelitian oleh Smith, dkk (2012) di Amerika Serikat, 4 dari 5 remaja sebagai ibu primipara memberikan ASI Eksklusif selama 9 hari, dan hanya satu remaja yang berhasil memberikan ASI Eksklusif selama enam bulan, karena memiliki niat yang sangat kuat untuk menyusui bayinya, menyatakan bahwa ASI yang terbaik untuk kehidupan bayinya dan tidak mengeluarkan uang. Bagi ibu primipara remaja yang berhenti menyusui sangat berkaitan dengan pengalaman mereka sebagai ibu yang memiliki pengetahuan kurang tentang dasar - dasar ASI, kurang keterampilan menyusui, pengalaman awal yang menyakitkan ketika mereka tidak siap melakukan pengeluaran ASI (Muskikah, 2014).

Transisi menjadi orang tua akan sulit bagi orang tua yang masih remaja, ibu primipara remaja pada minggu pertama masih belum siap menerima tugas- tugas barunya sebagai ibu. Hal ini sesuai dengan pendapat Rubin bahwa periode nifas dibagi menjadi tiga tahap tahap I (Taking in), tahap II (Taking hold), tahap III (letting go) pada tahap-tahap ini ibu sering terjadi perasaan tidak mahir dan tidak mampu dalam melakukan keterampilan perawatan bayi, misalnya menggendong bayi, memberikan ASI atau menyusui bayi, memandikan bayi, melakukan perawat tali pusat, dan memasang popok. Kesulitan yang dialami ibu primipara remaja meliputi kendala dalam merawat bayi, dan adanya faktor penghambat dari internal berupa : perasaan tidak mampu, pengalaman kurang, perasaan rendah diri, dan adanya tugas fase remaja yang belum terpenuhi, serta faktor eksternal berupa kurang dukungan suami atau keluarga, tenaga kesehatan dan kondisi bayi menurut Yunita \& Mahpolah (2013) dalam Hamidiyanti (2015).

Menurut Perinasia (2004) dalam Himawati dan Mawarti (2011) kemampuan ibu dalam menyusui dengan benar khususnya bagi ibu primipara sangat mendukung keberhasilan ibu dalam menyusui dengan teknik yang benar. Seorang ibu dengan bayi pertamanya mungkin akan mengalami masalah ketika menyusui yang sebetulnya hanya karena tidak tahu cara-cara menyusui yang benar. Cara menyusui berpengaruh terhadap keberhasilan menyusui. Banyak ibu dalam menyusui tidak dilakukan dengan benar, bahkan banyak pula ibu yang tidak bersedia 
menyusui bayinya. Kegagalan menyusui disebabkan oleh teknik dan posisi menyusui yang kurang tepat

Penelitian serupa yang dilakukan Aini (2011), di Desa Sumberanyar Kecamatan Nguling Kabupaten Pasuruan pada bulan April-Mei 2011 sebanyak 93 responden terdapat hubungan yang bermakna antara sikap ibu primipara dalam pemberian ASI kepada balita usia 0-24 bulan dengan teknik menyusui yang benar dengan nilai signifikasi dari hasil uji korelasi fisher exact yang didapatkan sebesar 0,000 .

Tujuan umum penelitian ini adalah untuk mengetahui Kemampuan Ibu Postpartum Primipara Remaja Dalam Menyusui Bayi Baru Lahir di Wilayah kerja UPT BLUD Puskesmas Narmada Kabupaten Lombok Barat NTB 2017.

\section{BAHAN DAN METODE}

\section{Lokasi dan Rancangan Penelitian}

Penelitian ini dilaksanakan di Wilayah kerja UPT BLUD Puskesmas Narmada Kabupaten Lombok Barat Provinsi Nusa Tenggara Barat. Jenis penelitian yang dilakukan observasional dengan rancangan cross sectional.

\section{Populasi dan Sampel}

Populasi dalam penelitian ini adalah semua Ibu bersalin di Wilayah kerja Puskesmas Narmada periode Mei sampai Juli 2017. Sampel penelitian ibu postpartum primipara remaja yang memenuhi kriteria inklusi dengan tekhnik purposive sampling yang berjumlah 40 orang.

\section{Pengumpulan Data}

Sumber data penelitian adalah data primer, diperoleh melalui observasi langsung menggunakan lembar observasi/chek list pada hari ke 3 dan hari ke 7. Analisis Data

Teknik analisis data yang digunakan adalah analisis univariat, bertujuan untuk melihat gambaran distribusi frekuensi karakteristik responden. Analisis bivariat bertujuan untuk melihat hubungan variabel independen terhadap variabel dependen dengan menggunakan uji regresi linear. 


\section{HASIL PENELITIAN}

\section{Analisis univariat}

Tabel 1. Distribusi Karakteristik Responden Ibu Postpartum Primipara Remaja di Wilayah Kerja Puskesmas Narmada Kabupaten Lombok Barat NTB

\begin{tabular}{|c|c|c|c|}
\hline No & Peubahan & Karakteristik & $\%$ \\
\hline 1 & Umur & $17,40 \pm 1,11$ & \\
\hline 2 & Umur kehamilan & $39,40 \pm 0,7$ & \\
\hline 3 & $\begin{array}{l}\text { Pendidikan } \\
\text { a. SD } \\
\text { b. SMP }\end{array}$ & $\begin{array}{c}5 \\
35\end{array}$ & $\begin{array}{l}12,5 \\
87,5\end{array}$ \\
\hline 4 & $\begin{array}{l}\text { Pekerjaan } \\
\text { a. Tidak Bekerja } \\
\text { b. Bekerja }\end{array}$ & $\begin{array}{c}33 \\
7\end{array}$ & $\begin{array}{l}82,5 \\
17,5\end{array}$ \\
\hline 5 & $\begin{array}{l}\text { Jenis Kelamin Bayi yang dilahirkan } \\
\text { a. Laki-laki } \\
\text { b. Perempuan }\end{array}$ & $\begin{array}{l}17 \\
23\end{array}$ & $\begin{array}{l}42,5 \\
57,5\end{array}$ \\
\hline 6 & $\begin{array}{l}\text { Berat bayi lahir Berat bayi hari ke } 3 \text { Berat } \\
\text { bayi hari ke } 7\end{array}$ & $\begin{array}{l}2962,5 \pm 234,9 \\
2887,5 \pm 276,5 \\
2942,7 \pm 322,5 \\
\end{array}$ & \\
\hline 7 & $\begin{array}{l}\text { Panjang Bayi Lahir Panjang Bayi Lahir } \\
\text { hari ke3 } \\
\text { Panjang Bayi Lahir hari ke } 7\end{array}$ & $\begin{array}{r}49,03 \pm 1,45 \\
49,03 \pm 1,45 \\
49,20 \pm 1,68\end{array}$ & \\
\hline
\end{tabular}

Sumber : Data Primer Wilayah kerja Puskesmas Narmada Kab.Lobar 2017

\begin{tabular}{ccccc} 
Kategori & \multicolumn{2}{c}{ Hari ke 3 } & \multicolumn{3}{c}{ Hari ke 7 } \\
\cline { 2 - 5 } kemampuan & $\mathrm{n}$ & $\%$ & $\mathrm{n}$ & $\%$ \\
\hline Tidak mampu & 23 & 57,5 & 22 & 55 \\
Mampu & 17 & 42,5 & 18 & 45 \\
Total & 40 & 100,0 & 40 & 100,0 \\
\hline
\end{tabular}

\section{Analisis Bivariat}

Tabel 2. Ditribusi Perubahan Kemampuan Ibu Postpartum Primipara Remaja Dalam menyusui Bayi Baru Lahir dari hari ke 3 ke hari ke 7 di Wilayah Kerja

\section{Model Summary}

\begin{tabular}{|l|l|l|c|c|}
\hline Model & $\mathrm{R}$ & R Square & Adjusted R Square & Std. Error of the Estimate \\
\hline 1 & $.576^{\mathrm{a}}$ & .332 & .315 & 228.996 \\
\hline
\end{tabular}

a. Predictors: (Constant), kategori kemampuan1

Sumber : data primer Wilayah kerja Puskesmas Narmada Kab.Lobar 2017 
Tabel 3. Hubungan Kemampuan Menyusui Bayi Baru Lahir Pada Hari Ke 3 Dengan Perkembangan Berat Bayi Pada Hari Ke 3

ANOVA ${ }^{b}$

\begin{tabular}{|c|c|c|c|c|c|}
\hline Model & Sum of Squares & Df & Mean Square & $\mathrm{F}$ & Sig. \\
\hline \begin{tabular}{l|l}
1 & Regression \\
\end{tabular} & 991064.578 & 1 & 991064.578 & \multirow[t]{3}{*}{18.899} & \multirow[t]{3}{*}{$.000^{\mathrm{a}}$} \\
\hline \begin{tabular}{l|l}
2 & Residual \\
\end{tabular} & 1992685.422 & 38 & 52439.090 & & \\
\hline Total & 2983750.000 & 39 & & & \\
\hline
\end{tabular}

a. Predictors: (Constant), kategori kemampuan1

b. Dependent Variable: bblahir3

Tabel 4. Hubungan Kemampuan Pemenuhan Kebutuhan Bayi Baru Lahir Pada Hari Ke 7 Dengan Perkembangan Berat Bayi Pada Hari Ke 7

Model Summary

\begin{tabular}{|l|r|l|l|c|}
\hline Model & & R Square & Adjusted R Square & Std. Error of the Estimate \\
\hline 1 & $.542^{\mathrm{a}}$ & & & 274.625 \\
\hline
\end{tabular}

a. Predictors: (Constant), kategori kemampuan2

ANOVA ${ }^{\mathbf{b}}$

\begin{tabular}{|c|c|c|c|c|c|c|}
\hline \multicolumn{2}{|l|}{ Model } & Sum of Squares & df & Mean Square & F & Sig. \\
\hline 1 & Regression & 1191840.909 & 1 & 1191840.909 & 15.803 & .000 a \\
\hline & Residual & 2865909.091 & 38 & 75418.660 & & \\
\hline & Total & 4057750.000 & 39 & & & \\
\hline
\end{tabular}

a. Predictors: (Constant), kategori kemampuan2

b. Dependent Variable: bblahir7

\section{PEMBAHASAN}

Dari data pendukung karakteristik responden dalam penelitian ini bahwa dari data umur remaja artinya umur $<20$ tahun resiko tinggi komplikasi kehamilan, persalinan dan nifas, secara psikologis kehamilan, persalinan dan masa nifas pada masa remaja juga berkaitan dengan kesiapan mental untuk menjadi ibu, terutama pada kelahiran anak pertama (Primipara). Ibu yang berusia Sebagian besar responen pendidikan rendah yaitu SMP 87,5\%, rendahnya tingkat pendidikan cenderung menyebabkan kurangnya pengetahuan ibu terkait perawatan bayi dan kurangnya persiapan dalam menyambut kelahiran sang bayi sehingga ibu membutuhkan dukungan informasi dalam masa nifas. Menurut Nursalam (2013) bahwa makin tinggi pendidikan seseorang, maka makin mudah menerima informasi sehangga makin banyak pula 
pengetahuan yang dimiliki, namun sebaliknya seseorang yang berpendidikan rendah akan mengalami hambatan dalam penyerapan informasi baik dari orang lain maupun media masa sehingga ilmu yang dimiliki juga lebih rendah yang berdampak pada kehidupannya.

Penelitian ini menunjukkan bahwa kemampuan responden dalam menyusui bayi baru lahir yang pada hari ke 3 ke hari ke 7 sebagian besar tetap tidak mampu yaitu sebanyak $55 \%$. Paparan hasil tersebut menunjukkan bahwa baik kemampuan hari ke 3 dan hari ke 7 sebagian besar responden tetap tidak mampu menyusui bayi baru lahir yang. Kemampuan merupakan kesanggupan, kecakapan, kekuatan untuk melakukan perbuatan sesuai kapasitasnya (Robbins, 2003 yang dikutip dari Silaban, 2010). Kemampuan dapat digolongkan pada dua jenis, yaitu kemampuan fisik dan kemampuan intelektual. Kemampuan intelektual (Intellectual ability) merupakan kemampuan melakukan aktivitas secara mental dan berkaitan dengan pengetahuan dan atau pendidikan dan kemampuan fisik (Physical ability) merupakan kemampuan melakukan aktivitas berdasarkan stamina kekuatan dan karakteristik fisik. Pengukuran kemampuan dapat dilakukan dengan pengamatan atau observasi (Cangelosi, 1995 dalam Silaban, 2010). Penelitian ini sejalan dengan penelitian Rahmawati (2017), di Yogyakarta populasi seluruh ibu menyusui yang memiliki bayi berumur 0-12 bulan yang melakukan kunjungan di Klinik Pratama Bina Sehat pada bulan Mei 2016 dan jumlah sampel 58 responden. Hasil penelitian menunjukkan dari 58 responden pada kemampuan menyusui bayi sebagian besar responden melakukan teknik menyusui dengan salah yaitu sebanyak 30 responden $(51,7 \%)$ dan yang benar dalam melakukan teknik menyusui yaitu sebanyak 28 responden $(48,2 \%)$.

Terbentuknya pola perilaku baru dan berkembangnya kemampuan seseorang terjadi melalui tahapan tertentu, yang dimulai dari pembentukan pengetahuan, sikap, sampai memiliki keterampilan baru. Kemampuan ibu merawat bayi baru lahir juga dipengaruhi oleh beberapa faktor yaitu pengalaman bersalin (primipara atau multipara), dukungan tenaga kesehatan, dukungan keluarga, dukungan suami yang terus menerus. Semua dukungan meningkatkan rasa percaya diri ibu, memberikan kenyamanan, memberikan keberhasilan dan kemampuan menyusui bayi baru lahir.

Menurut Bobak (2004) dalam Hamidiyanti (2015), meskipun banyak ibu remaja yang bahagia dengan proses kelahiran bayi ternyata banyak situasi atau kejadian yang menimbulkan kecemasan. Ibu primipara yang tidak berpengalaman cenderung akan menghadapi masalah kecil atau besar dalam menyesuaikan diri terhadap peran barunya dalam upaya merawat bayi. Keberhasilan atau kegagalan perawatan bayi sebagaian besar tergantung pada faktor tersedianya bantuan dan dukungan orang sekitar yang ada pada minggu. Ketika ibu primipara 
remaja mampu melakukan pemenuhan kebutuhan bayi baru lahir pada hari ke 3, ibu remaja didampingi dan dibantu oleh tenaga kesehatan (bidan), suami, mertua atau orang tua yang selalu ada, dukungan dari orang sekitar akan meningkatkan rasa percaya diri ibu, kemampuan ibu dalam menyusui bayinya, ketika hari ke 7 ibu postpartum primipara remaja dibiarkan mandiri maka akan mempengaruhi kemampuan ibu dalam menyusui bayi.

Pada penelitian ini peneliti mempunyai kriteria untuk mengambil responden salah satunya ibu nifas hari ke 3 dan hari ke 7, hal ini berkaitan dengan periode psikologi masa nifas menurut Rubin pada tahap II yaitu taking hold peride dimana terjadi perpindahan dari keadaan ketergantungan ke keadaan mandiri, ibu cendrung mengalami kecemasan, merasa kwatir akan ketidakmampuan dan rasa tanggung jawab dalam perawatan bayinya, perasaan ibu lebih sensitif sehingga mudah tersinggung dan merasa tidak mahir dalam melakukan keterampilan menyusui bayi baru lahir.

Hasil penelitian menunjukkan pada hari ke 3 menunjukkan bahwa berdasarkan hasil uji statistik dengan mempergunakan regresi linear bahwa ada pengaruh kemampuan menyusui bayi baru lahir pada hari ke 3 dengan berat badan bayi pada hari ke 3, dengan $p=0,000$ atau $p$ $<0,05$, dengan nilai koefisien regresi sebesar $R=0,576$. Artiya ada pengaruh yang signifikan kemampuan menyusui bayi baru lahir pada hari ke 3 dengan perkembangan berat bada bayi baru lahir pada hari ke 3. Hasil penelitian menunjukkan pada hari ke 7 menunjukkan bahwa berdasarkan hasil uji statistik dengan mempergunakan regresi linear bahwa ada pengaruh kemampuan menyusui bayi baru lahir pada hari ke 7 dengan berat badan bayi pada hari ke 7 , dengan $\mathrm{p}=0,000$ atau $\mathrm{p}<0,05$, dengan nilai koefisien regresi sebesar $\mathrm{R}=0,542$. Artiya ada pengaruh yang signifikan kemampuan pemenuhan kebutuhan bayi baru lahir pada hari ke 7 denganperkembangan berat bada bayi baru lahir pada hari ke 7 .

Kemampuan menyusui pada pada saat hari ke 3 rata-rata berat lahir bayi mengalami penurunan 75 ons dibandingkan pada saat lahir dan pada hari ke 7 mengalami peningkatan kembali. Sejalan dengan penelitian yang dikaukan oleh Astuti (2013) dengan ibu Postpartum 37 orang, rata - rata berat badan bayi mengalami penurunan 70 ons dan kemudian mengalami penambahan berat badan kembali. Hal ini sesuai dengan yang diungkapkan oleh Sugianto (2013) Deteksi dini tumbuh kembang anak juga ditempuh melalui pemeriksaan fisik rutin. Beberapa hal yang diperiksa pada anak, yakni tinggi badan, berat badan, tinggi badan dan berat badan berguna untuk mendeteksi gangguan pertumbuhan. Pada usia beberapa hari, berat badan bayi mengalami penurunan yang sifatnya normal, yaitu sekitar $10 \%$ dari berat badan waktu lahir. Hal ini disebabkan karena keluarnya mekonium dan air seni yang belum diimbangi dengan asupan yang mencukupi, misalnya produksi ASI yang belum lancar dan berat badan 
akan kembali pada hari kesepuluh. Pada usia 1-3 bulan kenaikan berat badan normal sekitar 200 gram perminggu. Panjang Badan bayi baru lahir normal adalah $45-50 \mathrm{~cm}$ dan berdasarkan kurva pertumbuhan yang diterbitkan oleh National Center for Health Statistics (NCHS), bayi akan mengalami penambahan panjang badan sekitar lebih kurang 2,5 cm setiap bulannya.

Berat badan bayi dapat turun beberapa hari setelah kelahirannya, hal ini dapat dikatakan normal dikarenakan tubuh bayi banyak mengandung air hingga akan dikeluarkan melalui urine setelah lahir. Meskipun demikian penurunan drastis harus tetap anda waspadai, seperti apakah berat badan pada bayi yang dikategorikan normal. Meskipun demikian, ibu tidak perlu khawatir dikarenakan tidak ada pengaruh yang berarti pada bayi apabila terjadi penurunan berat badat pada minggu pertama bayi dilahirkan. Penurunan berat badan bayi ini dimaksudkan untuk mengeluarkan cairan yang dibawa sejak lahir, bahkan dapat membuat adaptasi sistem pernapasan dan kardiovaskular menjadi seimbang. Tetapi itu terjadi hanya sebentar, karena setelah menurun berat badannya akan mulai bertambah. Umumnya berat badan bayi akan mulai bertambah dalam 7 sampai 14 hari setelah kelahiran. Batas kenaikan yang normal adalah untuk usia 0 hingga 3 bulan, berat badan akan bertambah kira-kira sebanyak 30 gram per hari. Jadi, dalam sebulan bayi akan mengalami kenaikan berat badan sekitar 900 gram (Carlis, 2013).

\section{KESIMPULAN DAN SARAN}

Ada pengaruh yang signifikan kemampuan menyusui bayi baru lahir dengan perkembangan berat bada bayi baru lahir. Bagi petugas kesehatan sebagai masukan agar tenaga kesehatan lebih meningkatkan asuhan kebidanan dengan tetap melakukan pendampingan selama masa nifas, melatih secara langsung kemampuan menyusui bayi baru lahir keterampilan perawatan bayi baru lahir dan mengevaluasi keterampilan ibu merawatan bayinya, memberikan dukungan dalam menjalankan peran barunya sebagi orang tua.

\section{DAFTAR PUSTAKA}

1. Astuti. Pengaruh Menyusui Terhadap Perubahan Berat Badan Ibu Post Partum Di Wilayah Kerja Puskesmas Sawit Kabupaten Boyolali. Skripsi diterbitkan di Surakarta. Fakultas Ilmu Kesehatan Universitas Muhammadiyah Surakarta, 2013.

2. BPS Lobar. Lombok Barat Dalam Angka 2014. Gerung: Badan Pusat Statistik Kabupaten Lombok Barat, 2014.

3. Hamidiyanti. Pengaruh Tingkat Kecemasan Pada Ibu Postpartum Primipara Remaja Terhadap Kemampuan Pemenuhan Kebutuhan Bayi Baru Lahir di Wilayah Kerja Puskesmas Narmada Kabupaten Lombok Barat NTB. Tesis diterbitkan di Makassar. Fakultas Kedokteran Universitas Hasanudin Makassar, 2015.

4. Herwani N. Gambaran Kemempuan Ibu Nifas Primipara Tentang Perawatan Bayi 
Sehari- hari di Kelurahan Bagan Pete Kota Jambi Tahun 2011. Jurnal Ilmiah Universitas Batanghari Jambi. Vol. 14 No. 1. Hal 58-63, 2014.

5. Kemenkes. Profil Kesehatan Indonesia 2012. Jakarta: Kementerian Kesehatan Republik Indonesia, 2013.

6. Oliveira P.S. \& Cordeiro M.M. Nursing Care Needs in the Postpartum Period Of Adolescent Mothers: Systematic Review. Jurnal of Nursing UFPE on line. Hal 39533961, 2014

7. Himawati dan Mawarti. Pengaruh Pendidikan Kesehatan Tentang Teknik Menyusui Terhadap Pengetahuan dan Perilaku Teknik Menyusui Pada Ibu Primipara di BPS Kecamatan Kalibawang Kulonprogo Tahun 2011. Skripsi. STIKES Aisyah Jogjakarta, 2011

8. Muskikah. Pengalaman Ibu Primipara Dalam Memberikan ASI Eksklusif di Wilayah Kerja Puskesmas Kelurahan Kembang Utara Jakarta Barat. Skripsi. Prodi Keperawatan Universitas Islam Negeri Syarif Hidayatullah Jakarta, 2014

9. Riskesdas. Badan Penelitian dan pengembangan Kesehatan Kementerian Kesehatan RI 2013. Jakarta : Kementerian Kesehatan Indonesia, 2013

10. Saliban A.S. Hubungan Tingkat Pengetahuan dengan Kemampuan Ibu Merawat Bayi Baru Lahir Selama Postpartum Dini di Klinik Bersalin Mariani Medan. Jurnal Ilmiah Keperawatan Universitas Sumatera Utara. Vol. 18. No. 15. Hal 15-28, 2010.

11. Sari A. Gambaran tingkat kecemasan ibu primipara remaja dalam kemampuan mengurus bayi baru lahir. Jurnal Kebidanan. Vol. 13. Hal 13-25, 2011.

12. Yunita, L., \& Mahpolah. Hubungan Umur dengan Tingkat Kecemasan Ibu Primipara pada Masa Nifas di Wilayah Kerja Puskesmas Kertak Hanyar. Dinamika Kesehatan Vol.12.No.12, 84-92, 2013 